\title{
9 Open Digital Badges and Reward Structures
}

\section{Daniel T. Hickey and Katerina Schenke}

\begin{abstract}
In recent years, web-enabled credentials for learning have emerged, primarily in the form of Open Badges. These new credentials can contain specific claims about competency, evidence supporting those claims, links to student work, and traces of engagement. Moreover, these credentials can be annotated, curated, shared, discussed, and endorsed over digital networks, which can provide additional meaning. However, digital badges have also reignited the simmering debate over rewards for learning. This is because they have been used by some and characterized by many as inherently "extrinsic" motivators. Our chapter considers this debate in light of a study that traced the development and evolution of 30 new Open Badge systems. Seven arguments are articulated: (1) digital badges are inherently more meaningful than grades and other credentials; (2) circulation in digital networks makes Open Badges particularly meaningful; (3) Open Badges are particularly consequential credentials; (4) the negative consequences of extrinsic rewards are overstated; (5) consideration of motivation and badges should focus primarily on social activity and secondarily on individual behavior and cognition; (6) situative models of engagement are ideal for studying digital credentials; and (7) the motivational impact of digital credentials should be studied across increasingly formal "levels."
\end{abstract}

Digital badges are a new kind of learning credential that can contain hyperlinks that provide easy access to relevant web-enabled information. In contrast to grades and degrees, digital badges can contain specific claims about competencies, details about how those competencies were acquired, and links to evidence such as completed work and traces of engagement. Recognizing

\footnotetext{
This research was primarily supported by grants from the John D. and Catherine T. MacArthur Foundation. Additional support was provided by a grant from the Indiana University Office of the Vice Provost for Research and by an assistantship from the Indiana University Department of Counseling and Educational Psychology. Individuals who contributed directly to the Design Principles Documentation Project included Christine Chow, Cindy Cogswell, Rebecca Itow, Nate Otto, Joshua Quick, Cathy Tran, James Willis III, and Suraj Uttamchandani. Rebecca Itow and Christopher Andrews assisted in the production of this manuscript.
} 
the need for standardization in this new credentialing system, Open Badges are issued in compliance with an agreed-upon set of metadata standards that allow badges to work across multiple platforms and make it easy for earners to annotate, curate, and share their badges over social networks. Curation and sharing of Open Badges in social networks can increase recognition and meaning (including "likes" and comments). The metadata standards also make it possible for the information contained in Open Badges to be examined and verified by both humans and computers.

Open Badges were introduced in 2012, with significant backing from the Digital Media and Learning (DML) initiative at the John D. and Catherine T. MacArthur Foundation, in close collaboration with the Mozilla Foundation. That year, a team at Mozilla worked with innovators from Peer to Peer University to draft the initial set of metadata standards. Also that year, MacArthur funded 30 pioneering educational programs to create and issue Open Badges (with supplemental funding from the Bill and Melinda Gates Foundation [2011] for a subset of the winning proposals). These events led to broad media coverage, in both mainstream venues (e.g., Carey, 2012; Eisenberg, 2011) and education-related outlets (e.g., Kolowich, 2014; Young, 2012).

By 2017, the use of Open Badges had grown steadily around the world. The MacArthur initiative had evolved into an ambitious youth-oriented, cityspecific badging platform known as Project $L R N G .{ }^{1}$ A more sophisticated set of metadata standards (Open Badges Specifications 2.0) and the maintenance of these new standards was assumed by the IMS Global Learning Consortium, the world's leading organization for setting educational technology standards. While some began referring to Open Badges as "micro-credentials," many use the term "digital badges" or simply "badges."

Predictably, the introduction of Open Badges rekindled the long-running debate over incentives for learning and, more generally, reward structures in education. This is in part because badges can be used as evidence-free "extrinsic" incentives for learning. As we will elaborate, such incentives have been shown in hundreds of empirical studies to undermine intrinsically motivated learning and subsequent free-choice engagement. The concerns about badges have been raised in widely cited critiques by influential writers, (e.g., Kohn, 2014; Resnick, 2012), including one that had been central in MacArthur's larger ten-year, \$250M initiative (Jenkins, 2012).

Our chapter will deeply explore these concerns over badges and motivation. The chapter opens with a summary of digital credentialing, an example badge system, and a summary of the concerns about badges and motivation. This is followed by an extended consideration of the motivational concerns in light of the conclusions drawn from a detailed study of all 30 Open Badge systems, funded in 2012 by the MacArthur Foundation. The chapter concludes with

1 Project LRNG's website can be accessed at www.lrng.org. 
seven arguments about using Open Badges to recognize and motivate learning, including arguments about future research that might explore and resolve the motivational concerns in learning contexts.

\section{Credentialing, Digital Credentials, and Endorsement}

Traditionally, diplomas, degrees, and certificates (as well as their associated grades and transcripts) are formally endorsed by outside accrediting bodies established for that purpose. Over the last century, conventional accrediting practices emerged alongside routines for hiring employees and advancing students. As such, these practices are often taken for granted by stakeholders and have become been quite resistant to change (Olneck, 2015). Conventional credentialing practices rely primarily on analog documents (e.g., grades and transcripts) and communication (e.g., conversations, phone calls, and emails), making credentialing expensive and inflexible for institutions and invisible to most educators (Anderson \& McGreal, 2012). Traditional credentials are also removed (i.e., "distal") from student learning experiences, and the admissions and hiring decisions associated with those credentials are practically invisible to students.

Because traditional credentialing practices are so distal, they push educators to introduce grades, points, mastery schemes, and other artificial means of recognizing and motivating learning that are closer (i.e., "proximal") to the learning experience. Arguably, this use of proximal motivators (which are not intrinsically meaningful) to give meaning to distal credentials is responsible for much of the practical debate over motivation and extrinsic rewards. Open Badges offer new opportunities to award credentials that achieve the goals of proximal assessment by attending to learners' interests and experiences, while also promising the kind of objective and aggregated evidence that admissions and hiring committees value. In this way, Open Badges have the potential to reduce the use of static credentials and promote a dynamic credentialing system that is more flexible, transparent, equitable, and motivational. Our chapter focuses on the motivational aspects of such a system.

\section{An Example Open Badge System}

An example of how Open Badges are being used to recognize and motivate learning was provided by the Supporter to Reporter (S2R) program. S2R is a youth sports journalism project in the United Kingdom that incorporated Open Badges as part of the initiative funded by MacArthur in 2012. Led by an educational non-profit organization known as DigitalMe, the S2R project had already been established in partnership with professional sporting associations, 


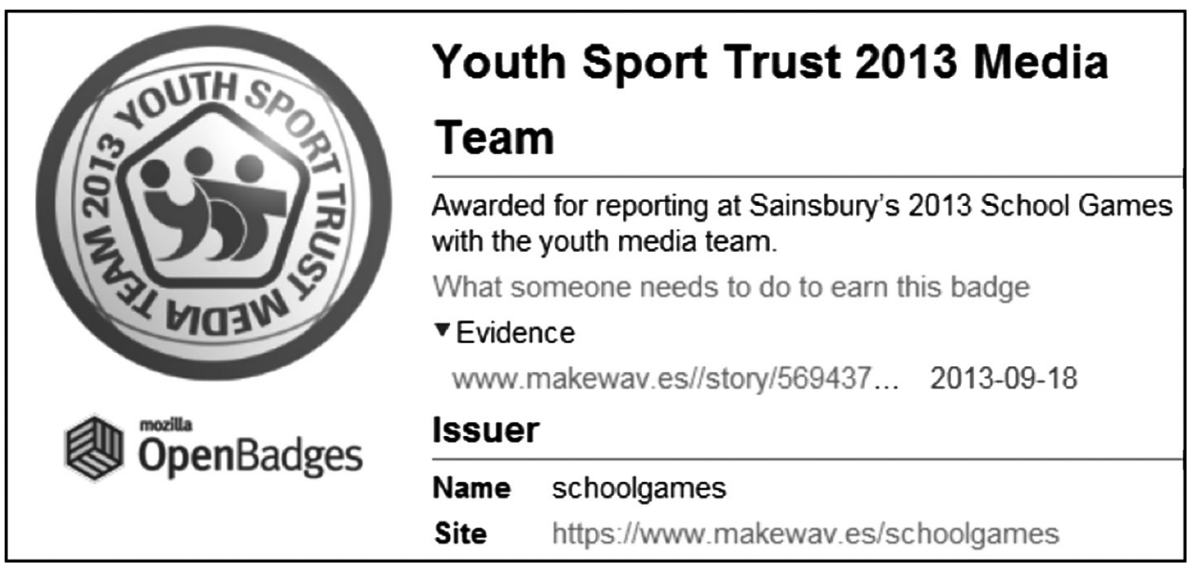

Figure 9.1. Content of a Supporter to Reporter Open Badge

amateur sporting clubs, and schools across the United Kingdom. ${ }^{2}$ DigitalMe created a sophisticated website where budding journalists and reporters could display various $\mathrm{S} 2 \mathrm{R}$ badges that they earned by creating and posting increasingly sophisticated media accounts of sporting events and interviews. Entry-level badges could be earned for simply posting a brief account of an event, while the highest-level badges granted earners field-level access at professional matches. The S2R website also offered a comprehensive set of free curricular resources to teachers, mentors, and learners.

Figure 9.1 displays the contents of an actual S2R badge, including an image, title, description, date issued, and three hyperlinks. The first hyperlink is to the page at the S2R website shown in Figure 9.2. That page displays the criteria that the earner met, a description of the evidence contained within the badge, a description of who awarded the badge, and the number of likes, comments, and views. The second hyperlink goes to the actual evidence (a video interview of a star athlete featured at a school tournament), along with the number of views and comments posted. The third hyperlink (embedded in the image) is to the page posted by the badge issuer (in this case, the school tournament) that allows the badge to be verified.

\section{Concerns over Digital Badges and Intrinsic Motivation}

Although Open Badges have certainly made significant inroads into credentialing, they have yet to be embraced by many educators and schools, and therefore have yet to be recognized by many admissions officers, hiring managers, and recruiters (Fong et al., 2016). Whereas there are certainly

2 The DigitalMe program's website can be accessed at www.digitalme.co.uk. 


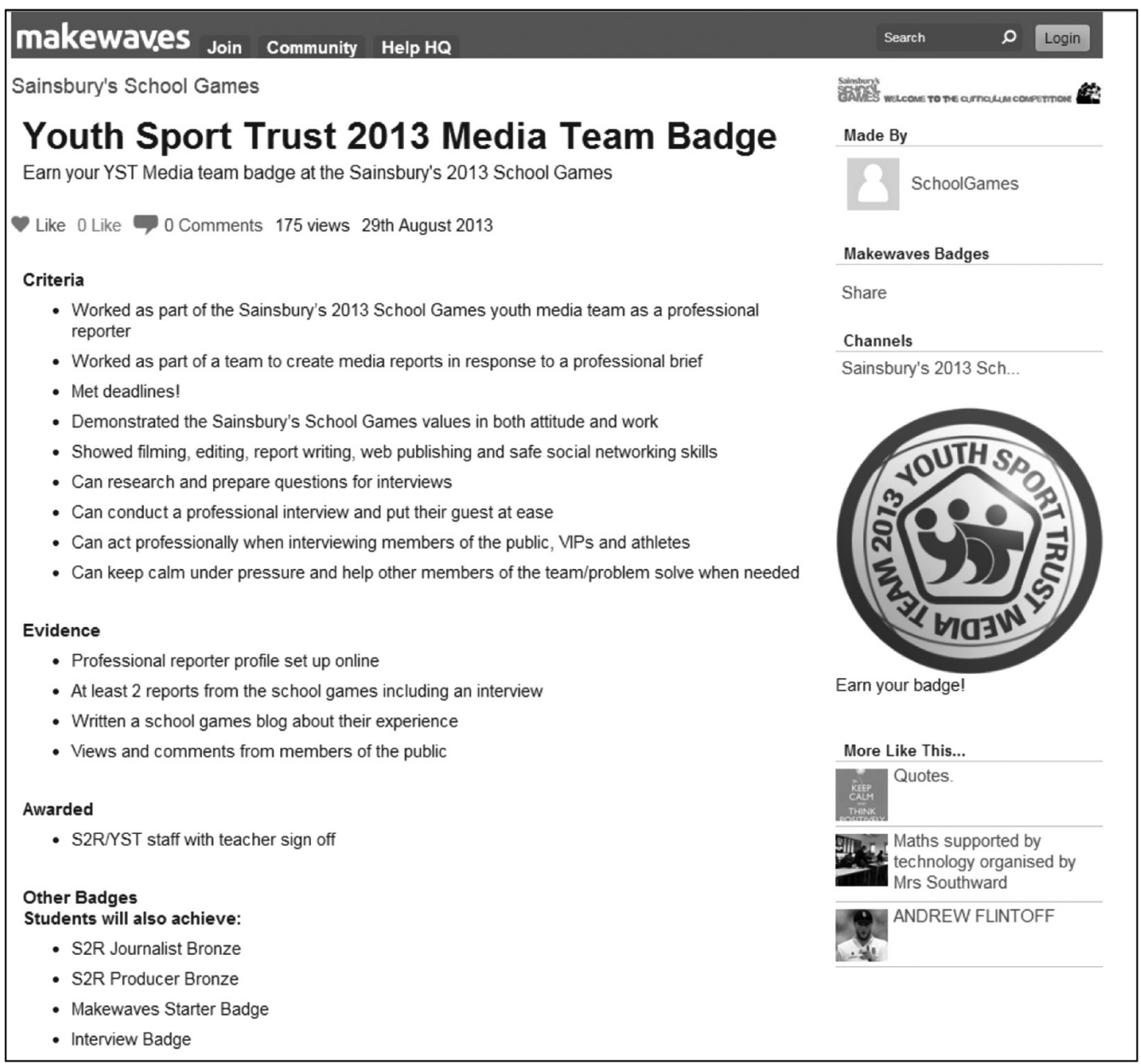

Figure 9.2. Criteria for earning the Supporter to Reporter Open Badge

other obstacles to the wider use of badges, the motivational concerns introduced earlier have generated resistance among some educators and schools. In a widely cited critique, then-director of the MIT Media Lab, Mitch Resnick, stated this concern over digital badges:

The problem, for me, lies in the role of badges as motivators. In many cases, educators are proposing badge systems in order to motivate students. It's easy to understand why educators are doing this: most students get excited and engaged by badges. But toward what end? And for how long? I worry that students will focus on accumulating badges rather than making connections with the ideas and material associated with the badges - the same way that students too often focus on grades in a class rather than the material in the class, or the points in an educational game rather than the ideas in the game. Simply engaging students is not enough. They need to be engaged for the right reasons. (Resnick, 2012) 
The influential education writer Alfie Kohn (2014) raised similar concerns in a keynote address at a London conference that was organized around Open Badges. Reflecting his several books on rewards for learning (e.g., Kohn, 1999), Kohn argued that prior research on extrinsic incentives had "already proven" that some of the most widely touted functions of badges (e.g., publically displaying competency, providing "pathways" for learning, and helping learners track their accomplishments) would have "devastating consequences for learning and learners, in both the near- and long-term."

A particularly stinging critique of digital badges came from media scholar Henry Jenkins (2012), who was an influential early participant in MacArthur's DML initiative. Jenkins worried that badges would be used in competitive "gamification" schemes that are antithetical to the informal "participatory cultures" (Jenkins et al., 2009) that the DML initiative had been promoting.

Empirical support for concerns about using digital badges as extrinsic motivators comes from studies of the "overjustification effect" (Lepper et al., 1973), whereby providing arbitrary (i.e., "extrinsic”) incentives for activities that individuals already find intrinsically motivating leads to reduced intrinsic motivation and to post-incentive disengagement. The classic example in the Lepper et al. study involved rewarding young children for playing with felttipped colored pens. Lepper et al. promised some children a reward (a "good player" ribbon, the expected reward condition) for playing with the markers. Later, when the children were invited again to play with the markers in the absence of any reward, the children who played while expecting the reward (i.e., had been "overjustified") played significantly less than the unexpected reward (a ribbon that had not been promised during the previous play) children or the no-reward children. This phenomenon and many variants have been documented in hundreds of experimental studies and compiled in multiple meta-analyses (e.g., Deci et al., 1999). Evidence of the overjustification effect has led many to embrace these concerns and other core assumptions of self-determination theory (Deci \& Ryan, 1985) and its broad implications for the way that learning is motivated and recognized (e.g., Cordova \& Lepper, 1996).

Although concerns about using digital badges as extrinsic rewards have yet to be examined in empirical studies (cf., Abramovich et al., 2013), such uses have been widely discussed in the educational media (e.g., Ash, 2012) and among educational bloggers (e.g., Ferlazzo, 2012; Gerstein, 2013). Given the extensive prior research on the overjustification effect and the influence of commentators like Alfie Kohn (and his workplace counterpart Pink, 2011), these concerns appear to be significant obstacles to both the study of and broader use of Open Badges and digital credentials more generally. The seven arguments presented in this chapter, particularly the fourth argument, are intended to provide guidance for addressing these concerns in both practice and research. 


\section{The Design Principles Documentation Project}

To explore the concerns about Open Badges and motivation to learn, we draw on our work in the Design Principles Documentation (DPD) Project. With funding from MacArthur, the DPD Project studied the 30 distinct badge system development efforts funded in 2012. The DPD Project documented the specific design practices and the more general design principles that emerged as each of the 30 efforts attempted to build badge systems in a diverse range of informal and formal educational contexts.

The DPD Project attempted to document the practical insights that emerged as each of the 30 efforts worked to bring their badge system to life, aiming to capture the phronetic narrative or "practical wisdom" (Halverson, 2004) that emerged as the individual projects designed and implemented their Open Badging systems. In doing so, the DPD Project aimed to capture the information that "evaporates" as technological features evolve and design teams dissolve (Kruchten, 2004). In other words, the study documented many of the most useful insights (e.g., seemingly good ideas that don't work out) that may have been lost in rapid iterating or as team members left. Useful complementary information about the MacArthur initiative and the 30 badge system designs can be found in Grant (2014).

\section{Methods of the DPD Project}

The DPD Project first carried out a content analysis to identify intended practices (described in each of the 30 proposals) for recognizing, assessing, motivating, and studying learning. The practices uncovered in each of the four areas were then organized (using a simple card sort) into more general badge design practices. In a series of structured interviews from 2012 to 2014, the project tracked whether each intended practice was implemented. In late 2014, after the badge design efforts had exhausted their funds and submitted a final report, the DPD Project attempted to determine whether each project had (1) created a functioning badge system where earners were actively earning badges, (2) created a partial badge system but not the larger learning ecosystem where badges were being earned by learners, or (3) suspended their efforts or otherwise had not created a fully functioning badge system. In late 2015, the DPD Project tried to determine which badge systems were "thriving" (i.e., new learners and badges being added, and badges being shared), "existing" (i.e., badges still earnable but no evidence of them being earned and shared), or "suspended" (i.e., no evidence of badges being offered). Partly to support the analyses presented in this chapter, the original proposals were then analyzed to derive four overarching types of badge systems that reflected the kinds of learning that the badges were intended to recognize (e.g., competency-based, inquiry-based, participation-based, or hybrid). The success with which the various practices were implemented and the relative success of the four different 
types of badge systems were used to derive more general principles for designing digital badge systems broadly and Open Badge systems specifically.

The DPD Project was ultimately a very complicated study, the findings of which are highly contextual. For example, eight of the 30 efforts were suspended without ever issuing any badges and nine of the 30 were deemed "partial" implementations. This introduced uncertainty as to whether particular practices were harder to implement (versus having been proposed within a badge system that was ultimately suspended because of other challenges). The motivational principles were particularly challenging to study, because most of the proposals did not specifically articulate their motivational practices or principles. This challenge required the DPD team to infer those principles based on the recognition and assessment practices that were more specifically articulated (Tran et al., 2014). As will be elaborated, inferring the motivational impact of the recognition and assessment practices necessarily required the DPD team to draw assumptions about the nature of learning and (therefore) motivation within each system.

The project's extended analyses of design practices for using Open Badges and the ultimate status of the 30 proposed Open Badging systems are detailed in a final project report (Hickey \& Willis, 2017). These analyses resulted in 57 initial design principles regarding "where badges work better" and included 17 principles for motivating learning with digital badges.

The next section provides a consolidated summary of the principles for motivating learning in digital Open Badge systems. This is followed by a more theoretical consideration of those principles, in light of the relative success of the four types of proposed badge systems.

\section{Badge Design Principles Derived from Motivational Practices}

Naturally, most of the motivational design principles were derived from practices used to "add value" to badges. For example, of the 30 badge system designs, three proposed to motivate learning with extrinsic rewards (i.e., a video library, Amazon gift certificates, and NASA certificates). All three of these Open Badge systems were ultimately implemented, meaning that the system had progressed to the point of awarding badges to actual learners. However, only the video library was actually offered to badge earners (by the Who Built America? project, for earning an entire set of badges in a history teacher professional development project). Moreover, even though it was an extrinsic reward, it was not entirely unrelated to the learning. As of 2015, that reward had never been claimed by any participant. The Amazon gift certificates and the NASA certificates were not offered in the final iteration of their respective systems. Leaders of these two efforts reported, in interviews, that these incentives were not offered because of concerns about the possibility that they would impact intrinsic motivation. These observations and the general concerns about incentives led to the relatively straightforward motivational design 
principle that badges work better when associated with intrinsically meaningful incentives rather than extrinsic rewards.

Similar to extrinsic rewards, five of the 30 proposed badge systems intended to motivate learning by associating badges with course credit. Only one system, an alliance of after-school programs, succeeded in doing so. The alliance associated badges with course credit by drawing on an existing system of assessments and program quality reviews. But the after-school badge system was promptly suspended because the students and teachers felt that the badges were redundant with grades (elaborated in Davis \& Singh, 2015). Detailed in the next section, this difficulty of associating badges with course grades was a central factor in the suspension of several systems, including all three of the proposed Open Badging environments associated with the Gates Foundation's Project Mastery initiative. These findings led to the potentially controversial principle that badges work better when learning is not motivated by formal course credit; these findings also supported the corresponding learning recognition principle badges work better when they present unique information and evidence.

One of the most challenging badge design practices to study was how to motivate learning with competition. Badges seem to naturally foster the public display of proficiency, which in turn may stimulate competition. The highest level S2R badge was both highly valued and hard to earn. Leaders of the S2R project reported that it certainly fostered competition among their most active participants, but there was no sort of "leader board" that prevented multiple participants from earning that badge. Several other systems succeeded in implementing such high-value badges. This included another youth journalism project (based in the United States) that motivated students with a comprehensive "All Star" badge (earners qualified for a field trip to Washington, DC). As we will elaborate, these badges were associated with "participationbased" learning; while earners recognized that they were competing to reach the highest level badge, there was no actual limit on the number of students who could earn it. In contrast, several competency-based systems proposed truly competitive point systems featuring actual leader boards. However, only one system, a gamified math drill and practice program, succeeded in doing so. This led to the tentative motivational principle that badges probably work better when competition concerns basic skills or participation in social practices, rather than learning from inquiry.

Of the 30 efforts, eight proposed to motivate learning with external opportunities. This included six efforts to formally associate their badges with internships, scholarships, and admissions. While three of those six implemented their badge system, none succeeded in securing any sort of agreement with institutions to award such opportunities, and none reported that their earners succeeded in using their badges to secure such opportunities on their own. In contrast, two of the six systems (including S2R) succeeded in issuing badges sufficiently rich with evidence that their earners were able to use the badges in successful applications for internships and admissions. These 
observations resulted in the design principle that badges work better when they motivate learning by containing claims and evidence that will help earners secure opportunities and internships.

A closely related badge design practice was to motivate learning with external endorsements. Of the 11 systems that proposed to do so, only five succeeded, including four that did so by drawing on existing institutional relationships. Just one of the efforts to secure endorsements from an external agency was successful in garnering support from an institution that could be explicitly stated on their badge. ${ }^{3}$ For the other six efforts, it appeared that the inability to formalize external endorsements was a major factor in the suspension of those badge systems. These observations led to the motivational principle that badges work better when they motivate as informal evidence-rich credentials that speak for themselves, and to a corresponding recognition principle that badges work better when external endorsements are based on existing institutional relationships.

Two inter-related practices for adding value to badges were: motivate learning with internal opportunities and motivate learning with entry-level badges for initial accomplishments. Of the ten efforts that proposed doing so, eight of the nine whose badge systems were implemented succeeded in implementing basic "entry-level" badges that unlocked additional, more valued opportunities inside of the learning context. This resulted in two design principles that helped respond to motivational concerns: Badges work better when they provide additional opportunities within the environment where the badges are issued, and badges work better when initial badges are easy to earn and provide access to more advanced badges.

Of the 30 projects, nine proposed to motivate learning by displaying badges publicly. All six of these nine projects that implemented their badge systems were able to implement this practice. In most cases, this included giving earners control over if and how the badges were displayed and, in some cases, adding additional information about those badges (e.g., by adding comments to the $\mathrm{S} 2 \mathrm{R}$ badge). These observations and the obvious value for self-determination led to the principle that badges work better when learners control how their badges are displayed publicly.

Two final motivational principles presented here concern two less obvious motivational practices for adding value to badges: motivate learning by recognizing disciplinary identities, and motivate learning by engaging with disciplinary communities. As elaborated in the final section of this chapter, contemporary theories of identity and motivation (Nolen et al., 2015; Oyserman, 2015) led the project to conclude that at least 13 of the 30 badge systems proposed one or both of these practices, and that all 10 of the 13 that implemented their badge system implemented these practices successfully. For example, the S2R "learning pathways" through the increasingly sophisticated

3 After extensive review, the National Oceanic and Atmospheric Administration allowed Planet Stewards to include the NOAA acronym (but not the NOAA logo) on their badges. 
badges were named after directly relevant professional roles (journalist, producer, and coach), and the S2R effort invested significant energy in building relationships with local sporting clubs. These observations led to the design principle that badges work better when used to help earners establish personal identities and engage with disciplinary and professional communities.

The remainder of the motivational design principles were rather tentative and were mostly associated with the assumed motivational impact of various assessment and goal-setting practices. These practices proved rather difficult to implement, and the design principles that emerged generally suggested that such practices should start with modest ambition and be based on proven examples that have successfully been implemented by others.

Each of these principles seems worthy of further study and refinement in the context of designing new Open Badge systems. Before proposing a model for doing so, we introduce some crucial theoretical issues that need to be addressed in order to carry out such research in a manner that might advance this new field.

\section{Badge Design Principles Derived from Comparing Types of Badge Systems}

The DPD Project was able to identify four different types of proposed badge systems by considering (1) the types of learning to be recognized, (2) the types of assessments to be used, and (3) the likely motivational consequences of those recognition and assessment practices.

Competency-based badge systems. Analysis of the 30 proposed badge systems revealed that seven intended to issue badges for competency-based learning. These systems proposed to (1) award badges for self-paced individualized mastery of relatively specific competencies, (2) use largely summative assessments of those competencies as criteria for awarding badges, and (3) use badges as primarily external and extrinsic motivators for learning (by formally associating them with course credit or external opportunities). Of these seven efforts, only two succeeded in implementing a complete system, in 2014. By 2015 , only one of the competency-based systems - Buzzmath, a gamification platform for drill and practice activities for middle school mathematics - was thriving. However, Buzzmath had decided not to use Open Badges (partly due to privacy concerns for minors); they offered internal badges on their website instead, as simple tokens of mastery.

There was a range of reasons why none of the seven competency-based badge systems created a thriving Open Badges system, and some of those reasons were explicitly motivational. For example, the Young Adult Library Services Administration successfully implemented Open Badges for mastery of the detailed competencies outlined by their organization. However, they 
reported that the badges were simply not valuable enough to motivate potential earners to (1) master those competencies, (2) generate evidence of that mastery, and (3) locate a qualified peer who was willing to review that evidence. More generally, it seemed that none of the competency-based Open Badge systems were sufficiently valued by the larger set of stakeholders so as to motivate the systemic changes needed (particularly to the assessment infrastructure) to support a thriving system. To this point, four of these efforts reported that the funding was insufficient to build the sophisticated technological tools needed to support self-paced mastery and the assessment of numerous competencies. This included three foundations that were provided additional support from the Gates Foundation.

These findings are timely because competency-based badges exemplify a broader trend toward competency-based education (CBE) within and outside of the United States. Most of the CBE variants (including "gamification") are organized around the self-paced mastery of specific measurable behaviors or mental associations (Everhart et al., 2014). CBE is often presented as an alternative to "traditional" schooling where credentials are said to be based on "seat time." Some influential observers have essentially equated the push to use Open Badges in educational settings with the movement toward CBE (e.g., Afterschool Alliance, 2015; American Council on Education, 2016; Blackburn et al., 2016; Duncan, 2011). Likewise, proponents of gamification have pointed out obvious connections with digital badges (e.g., Buckingham, 2014; Mallon, 2013; Metzger et al., 2016).

Notably, the three competency-based badge systems that received additional funding from the Gates Foundation were part of its Project Mastery initiative, which aimed to completely reorganize secondary learning around "proficiencybased pathways" (2011, p. 7). The DPD Project's findings regarding those three efforts were bolstered by a more extensive study from the Rand Corporation (Steele et al., 2014), which found that a central challenge for all three Gatessupported systems concerned equity in terms of who "benefits most under competency-based models" and that "educators at several sites reported that a competency-based approach may disproportionately favor highly motivated learners" (p. 49). ${ }^{4}$ These concerns echo similar concerns in a report by the Carnegie Foundation, which concluded that CBE "may privilege some students over others, ... be fine for highly motivated students, ... [and] could speed the progress of more accomplished and affluent students ... while their peers are left to struggle and possibly fall further behind" (Silva et al., 2015, p. 26).

4 Other credentialing tensions reported by Steele et al. (2014) included equating evidence from anytime/anywhere learning with conventional criteria, determining who can authorize credit, maintaining a common definition of proficiency, and building a sustainable model. They also pointed to other tensions, including technical, financial, and logistical barriers to efficiency. These later tensions echo problems identified by Leuba (2015) whereby most learning management systems and student information systems are organized around courses, making it difficult to organize learning around competencies. 
Inquiry-based badge systems. The DPD Project concluded that 12 of the 30 systems intended to issue badges for inquiry-based learning. These systems proposed to (1) award badges for completing larger projects or investigations that focused on higher-order conceptual understanding, (2) use more formative performance-based and portfolio-based assessment methods to evaluate that understanding, and (3) focus more on intrinsic sources of motivation like interest and curiosity. While these badge systems were intended to recognize both self-paced and group-based learning, their most salient feature was that the learning was organized around some sort of investigation or inquiry, typically around an extended project. For example, the teacher professional development activities for Who Built America? featured web-based historical investigations that included sophisticated portfolio assessment practices.

Of the 12 proposed inquiry-based badge systems, four had succeeded in implementing a complete Open Badge system by 2014, and four (including Who Built America?) appeared to be thriving in 2015. One notable commonality across the four thriving systems is that they found ways to minimize assessment demands. They did so by drawing on existing assessment practices, using computers, or significantly scaling back proposed practices for formally assessing learners' work. Conversely, a commonality across the eight efforts that did not implement badges or thrive was that they struggled to implement ambitious performance and portfolio assessment practices. Some of these assessment challenges were compounded by the realization that displaying evidence in Open Badges would direct additional scrutiny to the validity of that evidence, including the manner in which it was obtained.

These observations about the challenges of assessing inquiry-based learning and its many variants have important implications for motivation. Inquiryoriented learning is presumed to be intrinsically motivating because it can be organized around Malone and Lepper's (1987) factors for "making learning fun" (challenge, curiosity, control, and fantasy). Because such intrinsically motivated learning is typically open-ended and idiosyncratic, it has always been challenging to assess efficiently and reliably (e.g., Shavelson et al., 1992). The difficulties of assessing inquiry-based learning appear to be heightened when the claims and web-enabled evidence are circulated widely in Open Badges. Thus, while the inquiry-based badge systems may assuage the concerns about using badges as extrinsic motivators, they introduced hurdles of their own in implementing the assessments needed to award those badges and in gathering the evidence to include in them.

Participation-based badge systems. Of the 30 badge systems, five proposed to award participation-based badges. These systems proposed to (1) award badges primarily for participation in social learning and group projects, (2) emphasize peer-assessment and "crowdsourced" assessment practices, and (3) rely more on social and cultural forms of motivation. The S2R system exemplified such Open Badge systems. Consider that the first two criteria for earning a badge in Figure 9.2 start with "Worked as part of." From the outset, the S2R badge 
system was designed to motivate earners to create media artifacts that would gain page views, likes, and comments from peers and the public. Like S2R, none of the participation-based badge systems proposed to assess and recognize specific competencies. Rather, most badges were awarded for completing a course or a project, typically for groups of learners; while specific competencies were often included, they tended to be more tacitly assessed.

All five of the participation-based efforts had successfully implemented an Open Badge system by 2014, and by 2015 four of the Open Badge systems appeared to be thriving. It seems that the proposed badges were sufficiently valued by stakeholders to introduce and sustain the assessments and other new practices that were needed, and were sufficiently valued by learners to motivate them to carry out the activities needed to earn them.

Generally speaking, the participation-based badge systems aimed to allow each badge to speak for itself. Rather than struggling to formalize external opportunities and endorsements, the participation-based systems invested in creating social networks where viewers could decide for themselves whether the information contained in a specific badge supported the claims made by that badge.

Hybrid badge systems. The five remaining badge systems were categorized as "hybrids" because they employed features for assessing, recognizing, and motivating learning that were consistent with all perspectives. Akin to the inquiry-based systems, these efforts also encountered mixed outcomes that reinforce the conclusions about keeping individual assessment practices manageable. While two of those systems were thriving in 2015, their results did not add new insights to the motivational issues explored in our chapter.

New badge design principles. Looking across types of badge systems, the limited success of competency-based badges, the mixed results for the inquirybased and hybrid badges, and the success of the participation-based badges led to the design principle that badges work better where learning, recognition, and assessment practices are primarily sociocultural. By focusing more on social and cultural practices (versus individual practices), participation badges are relatively more consistent with the sociocultural perspectives that provided significant impetus for the MacArthur Foundation's larger DML initiative (e.g., Brown, 2012; Ito, 2012; Yowell, 2014). Similarly, the DPD Project was influenced by the new models of motivation that follow from sociocultural perspectives (Hickey, 2003; Nolen, et al., 2015; Yowell \& Smylie, 1999).

While the participation-based badges did include claims for specific competencies, these competencies were generally not assessed in isolation from other competencies or social activity. Rather, the participation-based badge systems left it up to educators or experts to make the judgment that someone who completed the particular program, activity, or course had indeed demonstrated those competencies or understandings. This appears to support a sixth general conclusion: Badges work better when awarded for completion of workshops, courses, or projects, rather than specific skills or competencies. 
The motivational appeal of participation-based badges was nicely articulated by S2R leader Lucy Neale Lewis. She stated that S2R "issues badges for taking on professional roles" and that "our supporters start off pretty low so we award badges for distance traveled rather than level achieved." Presaging the important new "Endorsements 2.0" feature (described later in this chapter), Neale also stated that

Open Badge Academy is about getting endorsements after you have earned a badge. People can come and add endorsements to the evidence. For example, one of the ways you can earn a badge is for an internship. You earn the badge on completing the internship. You can add that you thought it went well. The employer can also add an endorsement, adding additional feedback; your peers can do that too. The idea is building trust via multipoint validation. We like to use the e-Bay comparison when we talk about badges.

These findings led us to conclude that participation-based learning is uniquely (and possibly ideally) suited to take full advantage of the unique affordance of Open Badges for recognizing and motivating that learning. While Open Badges certainly may be useful for recognizing and motivating competencybased and inquiry-based learning, these findings suggest that caution is in order and that particular care needs to be directed at managing the significant (though rather different) assessment challenges they present.

It is important to note that participation badges are sometimes conflated with "attendance badges," awarded for showing up at a conference or a class (e.g., Thigpen, 2014, p. 6). We strongly agree that evidence-free badges should not be awarded simply for showing up. ${ }^{5}$ But this is very different than participation-based and "role-based" badges awarded for what Greeno (1998) and Hickey (2003) characterized as engaged participation, and which (ideally) contain evidence of that participation. In particular, we worry that conflating attendance and participation badges may obscure the significant motivational potential of the "entry-level" badges that most of the participation-based badge systems offer to new learners.

\section{Seven Arguments about Motivating Learning with Digital Badges}

Our general experience with the DPD Project and the findings we have shown lead us to advance the following five arguments about using Open Badges to

5 Bowen (2013) of Purdue University coined the term "carpetbadging" to refer to such practices, while Ravet (2015) characterized the practice as "spray and pray." This practice became widespread around 2013 and seems to have undermined the apparent value of digital badges for some stakeholders. The practice is encouraged by some commercial badge systems that make it cumbersome to upload unique evidence for each issued badge. 
recognize and motivate learning. These are followed by two arguments about the systematic study of efforts to do so with Open Badges.

\section{Argument \#1: Digital Badges Are Inherently Meaningful}

Arguably, the simmering tensions over extrinsic rewards and intrinsic motivation that were inflamed by digital badges are proxies for an enduring struggle between two antithetical paradigms of learning. The competency-based badge systems were generally consistent with traditional "associationist" perspectives that characterize knowledge in terms of specific behavioral or cognitive relationships (Anderson, 1982; Skinner, 1953). As such, associationist perspectives frame learning in terms of demonstrated mastery of those relationships, with relatively little concern about how learners form those relationships. As one influential proponent asserted, competency-based education is "agnostic as to the source of learning while maintaining clear and transparent learning standards" (Leuba, 2015).

In contrast, the inquiry-based badge systems were generally consistent with "constructivist" perspectives that characterize knowledge as higher-order cognitive schemata and conceptual understanding (Case, 1996). As such, constructivist perspectives frame learning as engaging in sense-making and exploration; such engagement is presumed to be necessary to reorganize prior knowledge in order to construct such schema. While this assumption underpins a vast array of approaches, these perspectives are united in their concern that extrinsic incentives will distort and undermine such intrinsically motivated engagement.

From our perspective, the enduring debate between associationist and constructivist perspective has been played out in the need to grade student work, and this need is largely driven by traditional credentialing practices. Early studies of the overjustification effect were a response to behaviorist educational practices, "token economies," and mastery learning schemes that had gained many adherents by the early 1970s (Greene et al., 1976). We assume that the overjustification effect can (and will) be replicated with digital badges that carry little meaning and are arbitrarily associated with certificates, degrees, or other distal motivators. But doing so ignores the fact that digital badges are intended to include detailed claims, evidence supporting those claims, and information about how that evidence was gathered. Such information can make digital badges more meaningful (i.e., "intrinsic") than the less meaningful (i.e., "extrinsic") rewards implicated in the overjustification effect.

Our point here is that the very design of digital badges encourages what Rieber (1996) called "endogenous" incentives that are directly relevant to the learning being incentivized while avoiding the "exogenous" incentives that are arbitrarily related. ${ }^{6}$ We encourage constructivist skeptics to factor this

6 It is worth noting that some proponents of gamification make similar arguments about not offering arbitrary exogenous incentives, particularly for activity that is already appealing to learners (e.g., Nicholson, 2012). 
into their concerns about Open Badges. Of course, our study suggested that intrinsically motivated constructivist learning presents its own challenges for obtaining evidence to include in digital badges. But we believe that it is inappropriate to equate digital and Open Badges with extrinsic rewards, CBE, or other related practices that are antithetical to constructivist approaches.

\section{Argument \#2: Open Digital Badges Are Particularly Meaningful}

Our second argument is that the unique characteristics of Open Badges can make them particularly meaningful and (therefore) motivational. The Open Badges Specifications allow badge systems that let earners control if and where their badges are shared, and make them responsible for organizing and annotating their badge collections. It seems to us that Kohn (2014) overlooked the motivational value of such earner control when he equated earners sharing badges with teachers publicly posting grades.

As illustrated by participation-based badges and elaborated in Casilli and Hickey (2016), the transparency that Open Badges introduce means that their value and credibility can be "crowdsourced." This means that Open Badges make traditional approaches to validation (of the evidence) and accreditation (of value) less relevant. While this introduces new uncertainties for adding meaning and value to credentials, it also opens up vast new possibilities for doing so. Consider that most young people are now able to very quickly learn the norms of new social networks. In particular, most are quite adept at learning (and shaping) the norms in their smaller network of friends within those larger networks. We believe that similar networked learning will occur as Open Badges become more widely used. We also suspect learners who are disenfranchised by existing credentialing practices will be able to learn about and participate in these networked credentialing practices more successfully.

\section{Argument \#3: Open Badges Are Particularly Consequential Credentials}

To reiterate, the DPD Project observed that most of the 30 badge design efforts struggled to (1) define learning outcomes and (2) design and implement assessments to generate evidence. This is not surprising, given that the introduction of assessments is typically quite consequential for the broader educational practices and ecosystems in which those assessments function (National Research Council, 2001; Shepard, 2000). This is because assessments push educators to think about the processes of learning instead of just the practices of teaching (Moss, 2003). As elaborated by Torrance (2012), these disruptions can be transformative (positively impacting the broader ecosystem), conformative (aligning the ecosystem to the assessments, which can be positive or negative, depending on the assessments), and deformative (negatively impacting the ecosystem).

Importantly, leaders of some of the 30 efforts reported that their assessment challenges were amplified by the recognition that they would be placing 
claims, evidence, and relevant information in Open Badges. Doing so makes this information public and readily accessible; leaders recognized that this transparency was likely to bring additional scrutiny to this information and the manner in which it was obtained. In this way, Open Badges are likely to enhance the positive and negative consequences of assessment practices for the broader ecosystem in which they function.

While their assessment challenges were different, both the competencybased systems and the inquiry-based systems struggled to overcome the challenges of designing and implementing their assessment systems. The competency-based systems struggled to design and implement the more summative assessments needed to provide evidence of numerous competencies, while the inquiry-based systems struggled to obtain convincing evidence of competency from completed work and learner-generated artifacts. In contrast, the participation-based systems focused more on exploiting the social recognition and motivation potential of Open Badges. In particular, these systems began exploring the way that social networks allow others to "like" and comment upon the badges and badge evidence. We believe that such "endorsement" practices have the potential to truly transform credentialing and its potential for motivating learning. We suspect that few stakeholders in the current credentialing enterprise have recognized the motivational potential of new "third party" endorsement made possible by Open Badges Specifications 2.0 (described in Hickey \& Otto, 2017). As argued in a foundational chapter on Open Badge endorsements:

The intentionally open structure of badge endorsement provides opportunities for a variety of different types of endorsers, including community organizations, employers, standards bodies, and groups that are re-envisioning how the value of learning is defined. (Everhart, et al., 2016, p. 232)

These arguments about endorsement and open recognition were further advanced at an international conference in 2016. The Bologna Open Recognition Declaration (2016) asserted that Open Badges "had proved the power of a simple, affordable, resilient and trustworthy technology to create an open recognition ecosystem working across countries, educational sectors, work, social environments and technologies" and "demonstrated that we have the means and the opportunity to put an end to the disparities of the recognition landscape."

\section{Argument \#4: The Negative Consequences of Extrinsic Rewards Are Overstated}

Despite our argument that Open Badges offer inherently meaningful incentives, it seems likely that Open Badges will still be used in ways that are relatively arbitrary and disconnected from engagement in learning. This seems particularly likely with the "closed" badge systems (e.g., Buzzmath and 
ClassBadges.com). ${ }^{7}$ Of course, behaviorally oriented theorists continue to dispute the empirical evidence against extrinsic incentives and question the very idea of intrinsically motivated engagement (Cameron et al., 2001). Furthermore, Hidi (2016) recently reviewed the evidence from neuroscience that documented the seemingly positive consequences of extrinsic rewards on brain activity. Hidi points out that while the social and educational psychological literature heavily emphasizes the negative effects of rewards on learning and motivation, the neuroscience literature suggests that our brains are "hardwired" to recognize and respond to rewards. As such, research that better understands the complicated nature of rewards is needed before any conclusive decisions about whether rewards are "good" or "bad" can be made.

Hidi's review bolsters the argument that even when badges function in a less meaningful and more arbitrary fashion, the potentially negative consequences for intrinsically motivated engagement in learning may be outweighed by other potentially positive consequences of extrinsic rewards. These include (1) the neurological response of individuals, (2) the behavioral engagement of individuals, and (3) the collective engagement of a learning community. In this way, badges can "jump-start" networked learning communities. If they do so, membership in and recognition by this community might motivate individual engagement that has all of the characteristics of intrinsic motivation. This "balancing" of incentives in actual learning contexts seems like a particularly fertile area for future research.

\section{Argument \#5: Focus Primarily on Social Activity and Secondarily on Individual Activity}

For complex reasons, we believe that considering the motivational value of Open Badges by starting with their impact on the way that individuals behave or process information is problematic, because any coherent consideration of motivation in learning contexts must reconcile (1) knowing and learning at the level of the individual with (2) knowing and learning at the level of larger social and cultural activity. Starting one's consideration of Open Badges at the level of the individual, one inevitably encounters the antithetical tensions between the associationist and constructivist models of learning. This, in turn, leads to corresponding tensions over learning (i.e., having those associations versus using those structures) and evidence of learning (i.e., demonstrating specific associations versus applying conceptual structures). While methodological and theoretical coherence may still be possible (by choosing one perspective or the other), practical tensions that will likely undermine efforts to transform education or produce useful design principles for motivating engagement will almost certainly be introduced.

7 ClassBadges.com launched in 2013; as of January 2017 the site was available for free use but was no longer supported. 
Another problem with starting one's consideration of badges and motivation with the behavior or cognition of individuals is that doing so necessarily characterizes social learning by "aggregating" assumptions about individual learning. This is why behavioral theorists use the notion of "meta-contingencies" (Lamal, 1990; Todorov, 2013), which characterizes social activity by aggregating assumptions about how contingencies (such as rewards) motivate individuals. Conversely, cognitive theorists like Bandura (2000) turn to aggregative characterizations of individual constructs like self-efficacy to characterize social activity in terms of "collective efficacy." In a cogent characterization of aggregative reconciliation of individual and social activity, Bandura (2000) asserted that " $[\mathrm{t}]$ here is no disembodied group mind that believes. Perceived collective efficacy resides in the minds of group members as the belief they have in common regarding their group's capability" (pp. 165-6).

In short, we contend that focusing on individual activity leads to aggregative reconciliation of social activity, and that this leads to an inaccurate and incomplete characterization of social activity. More specifically, we assume that social activity and human culture are indeed most accurately characterized with the notion of "disembodied group minds" (which was dismissed in Bandura, 2000, p. 165). Therefore, we believe that any effort to coherently and completely reconcile individual and social motivation for learning should start with social activity, and that this is particularly true with digitally networked learning.

\section{Argument \#6: Situative Models of Engagement Are Ideal for Studying Digital Credentials}

Our sixth argument is rooted in the nature of learning in digital networks. While all of the 30 badge design efforts involved networked computers, they varied in the extent to which the actual learning was "socially networked." Back in 2008, Brown and Adler (2008) stated that "the Web 2.0 is creating a new kind of participatory medium that is ideal for supporting multiple modes of learning" and that "the most profound impact of the Internet, an impact that has yet to be fully realized, is its ability to support and expand the various aspects of social learning" (p. 18). Brown and Adler made a clear distinction between socially networked learning from prior "Cartesian" views of learning that treat knowledge as "a kind of substance and that pedagogy concerns the best way to transfer this substance from teachers to students" (p. 19). Consistent with Lucy Neale Lewis' characterization of "role-based" badges above, Brown and Adler advanced a "participatory" view of networked learning that "involves not only 'learning about' the subject matter but 'learning to be a full participant in the field"” (p. 19).

As articulated by Xenos and Foot (2008), Web 2.0 digital networks are defined by transactive interactions (where the website provides content and information that is tailored to the information visitors provide) and shared control (between the producers of content and the collective users, so that 
content and user experience are co-produced by the website creator and visitors). This means the disciplinary knowledge created and stored in these networks is highly bound to that context, and the networks themselves evolve rapidly in response to evolving user needs. This in turn means that the important disciplinary knowledge in these settings is highly contextual (takes much of its meaning from the context in which it is used) and highly consequential (has obvious consequences for disciplinary practice, because many of the practices take place in similarly networked contexts). In this way, digital social networks necessarily create multiple "disembodied group minds" that transcend individual participants.

In addition to affording a more coherent depiction of individual and social activity, situative perspectives offer a coherent way to study all forms of individual activity. The "situative synthesis" in Greeno (1998) treats all forms of individual knowing (i.e., the objective behavior of individuals and the way human minds appear to process information) as "special cases" of social activity. All learning is fundamentally situated in the social, technological, and material contexts where it is created, learned, and used. Put differently, this perspective suggests that individual knowledge is "secondary" to knowledge that is primarily social. This allows educational innovators to primarily focus on engaged participation in whatever disciplinary practices are the focus of the innovation. Contrary to many characterizations, this participation can occur in social isolation, as individuals use the socially constructed tools of the discipline with increasing success.

In learning contexts, credentials and incentives are likely to be accompanied by discourse among educators and learners when they are introduced, offered, and earned. This discourse can be more or less disciplinary (concerning the ideas, terms, content, resources, and practices that define the particular discipline). From a situative perspective, discourse that is more disciplinary is always better than discourse that is less disciplinary. While the theory behind this idea might be complex, its practical implication is quite simple: Is the discourse associated with the credential more or less disciplinary? If the discourse associated with the incentive concerns the discipline (e.g. "your connections between and were very strong") then the incentive is likely desirable. If the discourse does not concern the discipline (e.g., "you were late" or "you failed") then the incentive is likely undesirable.

\section{Argument \#7: Study Motivation and Digital Credentials at Three Levels}

Our final argument is that the motivational consequences of digital badges should be understood and studied at three increasingly formal "levels." At the "close" level, one first examines the extent to which badges (introducing, offering, earning, or endorsing them) are associated with productive forms of disciplinary engagement. Engle and Conant's (2002) study of productive disciplinary engagement (PDE) suggests looking for discourse that makes 
connections between disciplinary knowledge (abstractions that experts "know" independent of context) and learners' nascent disciplinary practices (what experts "do" in particular disciplinary contexts where their expertise can be recognized). Likewise, Engle's (2006) study of generative learning points to discourse that (1) establishes common ground with content and differential trajectories of participation, (2) temporally frames engagement around prior experiences and future goals, and (3) journalistically frames participants as authors and contributors to a larger community.

At the second "proximal" level, one then examines whether PDE and generative learning is "echoed" in intrinsically motivated engagement and situational interest (Hidi \& Anderson, 2014). Such engagement and situational interest can be readily captured using self-reports during or immediately after the activities associated with the badges. Because such self-reports can be automatically offered and analyzed in networked learning contexts, establishing baseline scores across multiple activities and learners on simple Likertscale items is possible. The baselines can reveal scores that are relatively higher or lower than the baselines for particular activities carried out to earn badges.

At the third "distal" level, the credentialing system that emerges from iterative refinements across the close and proximal level systems can then be more formally evaluated by comparing such systems to a similar learning environment that does not include those credentials (or some other comparison environment that targets the same disciplinary standards) according to more stable, longer-term outcomes. These include changes in personal interest in the particular discipline (Hidi \& Renninger, 2006), as well as changes in subsequent free-choice engagement in activities associated with the discipline.

A version of such a multi-level approach was employed in a quasiexperimental study of incentives and badges reported by Filsecker and Hickey (2014) that was carried out with the Quest Atlantis STEM educational videogame (Barab et al., 2007). This study compared badge-based incentives (classroom leader boards and avatar badges that offered special opportunities) with appeals to curiosity and challenge. Results across two matched pairs of classes revealed that the incentives were indeed associated with significantly higher levels of PDE (as indicated by increased and more appropriate use of targeted scientific concepts in player-submitted "field reports"), slightly higher levels of self-reported intrinsic motivation when completing those reports, and slightly more positive changes in self-reported individual interest in learning about the STEM discipline and problems.

As best illustrated in a similar study of multiple levels of assessment (Hickey \& Zuiker, 2012), the "echoes" of impact across different kinds of evidence are useful for distinguishing systematic impact from innovation from the random variation that is usually present in authentic learning contexts. This provides useful evidence for guiding iterative refinements of recognition and assessment practices, which in turn can deliver useful design principles that can serve as the starting points for others. 
This nascent "multiple-levels" model of motivation draws on some of the same ideas and concerns behind more well-known "multi-level" considerations (e.g., Chen \& Kanfer, 2006; Järvelä et al., 2010). But the model proposed here diverges in its embrace of a situative synthesis, resolutely interventionist goals, and design-based research methods. The method is complex and presents tensions between interventionist goals for iterative refinement and naturalistic goals for generalizable results. But it accrues design principles that extend beyond particular projects. When these design principles are shared, along with examples and information about the most relevant features of the example context, these principles can be readily used and extended by others.

Fortunately, in networked learning settings, the discourse associated with credentials can be captured and searched by machines. We are particularly excited that digital badges promise to hold and organize evidence of learning (elaborated in Hickey \& Willis, 2015). If the multi-level model summarized here is applied to digital badges, the evidence of learning contained in the issued badges is immediately useable to study motivation. When coupled with the forthcoming features of Open Badges 2.0, tremendous potential for transforming learning and education is promised.

\section{Concluding Thoughts}

Our primary conclusions from this research are represented by the seven design principles given. To reiterate, these conclusions emerged when considering the concerns that critics and skeptics have raised about the potentially negative consequences of digital badges for intrinsic motivation in light of the findings of the Design Principles Documentation Project. The DPD Project concluded that seven of the 30 badge system designs primarily intended to use badges as relatively extrinsic incentives (within competency-based ecosystems). But the fact that 23 other systems did not attempt to use badges in this manner suggests to us that the concerns about extrinsic rewards should be directed at the design of broader educational ecosystems rather than badges. Put differently, our evidence supports the conclusion that Open Badges have provided a new proxy for the enduring debate over reward structures in educational ecosystems; our argument is that equating badges and reward structures in this fashion is inappropriate and is impeding the important research and innovation required to identify needed principles for using digital credentials most effectively.

It is important to note that some leaders within the Open Badges community (particularly Ravet, 2014) have expressed concerns that introducing Open Badges into constructivist ecosystems might lead them to be transformed ("deformed" in Torrance, 2012) into competency-based ecosystems (and presumably the corresponding reward structures). Our data did not provide support for that concern, in that the inquiry-based systems did not report or appear to shift towards more specific measurable competencies because of 
badges. However, tension with conventional summative assessments has long been a central issue for proponents of inquiry-based education and other such constructivist approaches (e.g., Gardner, 1992). Thus, another general conclusion is that Open Badges provide both the impetus and the context for educators and innovators to make new progress on resolving these enduring tensions. To reiterate, we believe that situative theories and the new forms of evidence of learning contained in (and represented by) digital badges present a promising path forward in this regard.

Two rather nuanced conclusions may help guide future studies of badges and reward structures. Our first conclusion is that Open Badges are likely to draw additional scrutiny to claims and evidence, and to the manner in which such information is obtained. Our second conclusion is that the transparency afforded by this new scrutiny is likely to enhance the consequences of assessment practices for the larger educational ecosystems that those assessments serve. These consequences can be both positive and negative; some consequences might be positive from certain perspectives and negative from other perspectives. These nuances call for studies that are well-theorized and carefully designed, rather than simplistic comparison studies that introduce badges and then examine a few outcomes.

We close by reiterating that we did not reach any strong conclusions regarding competency-based versus inquiry-based badge systems. While the competency-based efforts had a particularly difficult time implementing their badge systems, most of those efforts also struggled more generally because they also had to overcome the fundamental orientation of their broader school systems towards courses and cohorts. Of course, our data did suggest that it was easier to issue badges for the completion of courses and projects with cohorts of learners, and provided some support for the concerns raised elsewhere about the limitations of self-paced competencybased education (and the reward structures that they call for). But we believe that self-paced competency-based learning is ideal for some learning goals and contexts, and is inevitable in many more contexts, regardless of concerns raised by others. We hope that this chapter provides helpful guidance for using digital badges across the entire range of educational approaches.

\section{References}

Abramovich, S., Schunn, C., \& Higashi, R. M. (2013). Are badges useful in education? It depends upon the type of badge and expertise of learner. Educational Technology Research and Development, 61(2), 217-32. doi: 10.1007/ s11423-013-9289-2.

Afterschool Alliance (2015). Digital badges in afterschool: Connecting learning in a connected world. [Report]. Retrieved from www.afterschoolalliance.org/documents/DigitalBadgesInAfterschool.pdf. 
American Council on Education (2016). Quality dimensions for connected credentials. Washington, DC. Retrieved from http://connectingcredentials.org/wp-content/ uploads/2016/04/Quality-Dimensions-for-Connected-Credentials.pdf.

Anderson, J. R. (1982). Acquisition of cognitive skill. Psychological Review, 89(4), 369-406. doi: 10.1037/0033-295X.89.4.369.

Anderson, T. \& McGreal, R. (2012). Disruptive pedagogies and technologies in universities. Educational Technology \& Society, 15(4), 380-89.

Ash, K. (2012, June 13). "Digital badges" would represent student skill acquisition; Initiatives seek to give students permanent online records for developing specific skills. Education Week Digital Directions 5(3), pp. 24-25, 28, 30. Retrieved from https://www.edweek.org/dd/articles/2012/06/13/03badges.h05.html

Bandura, A. (2000). Exercise of human agency through collective efficacy. Current Directions in Psychological Science, 9(3), 75-8.

Barab, S., Zuiker, S., Warren, S., Hickey, D., Ingram-Goble, A., Kwon, E. J., ... Herring, S. C. (2007). Situationally embodied curriculum: Relating formalisms and contexts. Science Education, 91(5), 750-82. doi: 10.1002/sce.20217.

Blackburn, R. D., Porto, S. C., \& Thompson, J. J. (2016). Competency-based education and the relationship to digital badges. In L. Y. Muilenburg \& Z. L. Berge (Eds.), Digital badges in education: Trends, issues, and cases (pp. 30-8). New York, NY: Routledge.

Bologna Open Recognition Declaration (2016). Author. Retrieved from www.openrecognition.org.

Bowen, K. (2013). "Carpetbadging" - why metadata is so important when it comes to \#openbadges [Twitter post]. Retrieved from https://twitter.com/kyledbowen/ status/336577 520449245185 .

Brown, J. S. (2012). Cultivating the entrepreneurial learner in the 21 st century. [YouTube video]. Keynote address at the 2012 Digital Media and Learning Conference. Retrieved from https://www.youtube.com/watch?v=SoRV0BEwvEU.

Brown, J. S. \& Adler, R. P (2008). Open education, the long tail, and learning 2.0. EDUCAUSE Review, 43(1), 16-20.

Buckingham, J. (2014). Open digital badges for the uninitiated. The Electronic Journal for English as a Second Language, 18(1), 1-11.

Cameron, J., Banko, K. M., \& Pierce, W. D. (2001). Pervasive negative effects of rewards on intrinsic motivation: The myth continues. The Behavior Analyst, 24(1), 1-44.

Carey, K. (2012). Show me your badge. The New York Times. Retrieved from https:// www.nytimes.com/2012/11/04/education/edlife/show-me-your-badge.html.

Case, R. (1996). Changing views of knowledge and their impact on educational research and practice. In D. R. Olson \& N. Torrance (Eds.), Handbook of education and human development (pp. 75-99). Cambridge, MA: Blackwell.

Casilli, C. \& Hickey, D. (2016). Transcending conventional credentialing and assessment paradigms with information-rich digital badges. The Information Society, 32(2), 117-29. doi: 10.1080/01972243.2016.1130500.

Chen, G. \& Kanfer, R. (2006). Toward a systems theory of motivated behavior in work teams. Research in Organizational Behavior, 27, 223-67. doi: 10.1016/ s0191-3085(06)27006-0.

Cordova, D. I. \& Lepper, M. R. (1996). Intrinsic motivation and the process of learning: Beneficial effects of contextualization, personalization, and choice. Journal of Educational Psychology, 88(4), 715-30. 
Davis, K. \& Singh, S. (2015). Digital badges in afterschool learning: Documenting the perspectives and experiences of students and educators. Computers \& Education, 88, 72-83. doi: 10.1016/j.compedu/2015.04.011.

Deci, E. L., Koestner, R., \& Ryan, R. M. (1999). A meta-analytic review of experiments examining the effects of extrinsic rewards on intrinsic motivation. Psychological Bulletin, 125(6), 627-68. doi: 10.1037/0033-2909.125.6.627.

Deci, E. L. \& Ryan, R. M. (1985). The general causality orientations scale: Selfdetermination in personality. Journal of Research in Personality, 19(2), 10934. doi: 10.1016/0092-6566(85).

Duncan, A. (2011). Digital Badges for Learning. Opening remarks and DML 2012 competition event transcript. Retrieved from www.ed.gov/news/speeches/ digital-badges-learning.

Eisenberg, A. (2011, November 19). For job hunters, digital merit badges. The New York Times, p. BU3. Retrieved from https://www.nytimes.com/2011/11/20/ business/digital-badges-may-highlight-job-seekers-skills.html

Engle, R. A. (2006). Framing interactions to foster generative learning: A situative explanation of transfer in a community of learners classroom. The Journal of the Learning Sciences, 15(4), 451-498. http://doi.org/10.1207/s15327809j1s1504

Engle, R. A. \& Conant, F. R. (2002). Guiding principles for fostering productive disciplinary engagement: Explaining an emergent argument in a community of learners classroom. Cognition and Instruction, 20(4), 399-483. doi: 10.1207/ S1532690XCI2004_1.

Everhart, D., Derryberry, A., Knight, E., \& Lee, S. (2016). The role of endorsement in Open Badges ecosystems. In D. Ifenthaler, N. Belin-Mularski, \& D. Mah, (Eds.), Foundation of digital badges and micro-credentials (pp. 221-35). New York, NY: Springer.

Everhart, D., Sandeen, C., Seymour, D., \& Yoshino, K. (2014). Clarifying competencybased education terms: A lexicon. Blackboard.com. Retrieved from http:// bbbb.blackboard.com/Competency-based-education-definitions.

Ferlazzo, L. (2012). The dangers of "gamification" in education. Edublogs. Retrieved from http://larryferlazzo.edublogs.org/2012/02/26/the-dangers-of-gamificationin-education/.

Filsecker, M. \& Hickey, D. T. (2014). A multilevel analysis of the effects of external rewards on elementary students' motivation, engagement and learning in an educational game. Computers \& Education, 75, 136-48. doi: 10.1016/j .compedu.2014.02.008.

Fong, J., Janzow, P., \& Peck, K. (2016). Demographic shifts in educational demand and the rise of alternative credentials. University Professional and Continuing Education Association. Retrieved from http://upcea.edu/wp-content/ uploads/2017/05/Demographic-Shifts-in-Educational-Demand-and-theRise-of-Alternative-Credentials.pdf.

Gardner, H. (1992). Assessment in context: The alternative to standardized testing. In B. R. Gifford \& M. C. O'Connor (Eds.), Changing assessments: Alternative views of aptitude, achievement, and instruction (pp. 77-120). Boston, MA: Kluwer Academic Publishers.

Gates Foundation. (2011). Supporting students: Investing in innovation and quality. College Ready Monograph Series. Seattle, WA. Retrieved from https://docs .gatesfoundation.org/documents/supporting-students.pdf.

Gerstein, J. (2013). I Don’t Get Digital Badges. User generated education [blog]. Retrieved from https://usergeneratededucation.wordpress.com/2013/03/16/ i-dont-get-digital-badges. 
Grant, S. (2014). What counts As learning. Digital Median and Learning Research Hub. Retrieved from https://dmlhub.net/publications/what-counts-learning.

Greene, D., Sternberg, B., \& Lepper, M. R. (1976). Overjustification in a token economy. Journal of Personality and Social Psychology, 34(6), 1219-34. doi: 10.1037/0022-3514.34.6.1219.

Greeno, J. G. (1998). The situativity of knowing, learning, and research. American Psychologist, 53(1), 5-26. doi: 10.1037/0003-066X.53.1.5.

Halverson, R. (2004). Accessing, documenting, and communicating practical wisdom: The phronesis of school leadership practice. American Journal of Education, 111(1), 90-121. doi: 0195-6744/2004/11101-0004\$05.00

Hickey, D. T. (2003). Engaged participation versus marginal nonparticipation: A stridently sociocultural approach to achievement motivation. The Elementary School Journal, 103(4), 401-29. doi: 0013-5984/2003/10304-0006\$05

Hickey, D. T. \& Otto, N. (2017). "Endorsement 2.0" is about to transform eCredentials. EDUCAUSE Review [online]. Retrieved from https:// er.educause.edu/articles/2017/2/endorsement-2-taking-open-badges-andecredentials-to-the-next-level.

Hickey, D. T. \& Willis, J. E. (2015). Research designs for studying individual and collaborative learning with digital badges. In Proceedings of the Second Annual Open Badges in Education Workshop, Poughkeepsie, NY (pp. 36-40). Retrieved from http://ceur-ws.org/Vol-1358/paper5.pdf.

Hickey, D. T. \& Willis, J. E. (2017). Where badges appear to work better. Final Report of the Design Principles Documentation Project. Indiana University. Center for Research on Learning and Technology. Retrieved from http://bit .ly/2DPDfinalreport.

Hickey, D. T. \& Zuiker, S. J. (2012). Multilevel assessment for discourse, understanding, and achievement. Journal of the Learning Sciences, 21(4), 522-82. doi: 10.1080/10508406.2011.652320.

Hidi, S. (2016). Revisiting the role of rewards in motivation and learning: Implications of neuroscientific research. Educational Psychology Review, 28(1), 61-93. doi: 10.1007/s10648-015-9307-5.

Hidi, S. \& Anderson, V. (2014). Situational interest and its impact on reading and expository writing. In A. Renninger, S. Hidi, \& A. Krapp, (Eds.), The Role of interest in learning and development (pp. 215-38). New York, NY: Psychology Press. (Reprinted from 1992).

Hidi, S. \& Renninger, K. A. (2006). The four-phase model of interest development. Educational Psychologist, 41(2), 111-27. doi: 10.1207/s15326985ep4102_4.

Ito, M. (2012). Reflections on DML 2012 and a vision of educational change. [blog post at DML Central]. Retrieved from http://dmlcentral.net/blog/mimi-ito/ reflections-dml2012-and-visions-educational-change.

Järvelä, S., Volet, S., \& Järvenoja, H. (2010). Research on motivation in collaborative learning: Moving beyond the cognitive-situative divide and combining individual and social processes. Educational Psychologist, 45(1), 15-27. doi: $10.1080 / 00461520903433539$.

Jenkins, H. (2012). How to earn your skeptic "badge." Confessions of an Aca-Fan. The official blog of Henry Jenkins. Retrieved from http://henryjenkins .org/2012/03/how_to_earn_your_skeptic_badge.html.

Jenkins, H., Purushotma, R., Weigel, M., Clinton, K., \& Robison, A. J. (2009). Confronting the challenges of participatory culture: Media education for the 21 st century. Cambridge, MA: MIT Press. 
Kohn, A. (1999). Punished by rewards: The trouble with gold stars, incentive plans, A's, praise, and other bribes. Boston, MA: Houghton Mifflin Harcourt.

Kohn, A. (2014). Keynote presentation at the $12^{\text {th }}$ Annual e-Portfolio, Open Badges, and Identity Conference, London, England. Retrieved from www.youtube .com/watch?v=p_98XcxJqkw.

Kolowich, S. (2014). Can digital "badges" and "nanodegrees" protect job seekers from a first-round knockout? Chronicle of Higher Education. Retrieved from www .chronicle.com/article/Can-Digital-Badges-and/150257.

Kruchten, P. (2004). The rational unified process: An introduction. New York, NY: Addison-Wesley.

Lamal, P. A. (1990). Behavioral analysis of societies and cultural practices. New York, NY: Taylor \& Francis.

Lepper, M. R., Greene, D., \& Nisbett, R. E. (1973). Undermining children's intrinsic interest with extrinsic reward: A test of the "overjustification" hypothesis. Journal of Personality and Social Psychology, 28(1), 129-37.

Leuba, M. (2015). Competency-based education: Technology challenges and opportunities. EDUCAUSE Review [online]. Retrieved from http://er .educause.edu/articles/2015/10/competency-based-education-technologychallenges-and-opportunities.

Mallon, M. (2013). Gaming and gamification. Public Services Quarterly, 9(3), 210-21. doi: 10.1080/15228959.2013.815502.

Malone, T. W. \& Lepper, M. R. (1987). Making learning fun: A taxonomy of intrinsic motivations for learning. In R. E. Snow \& M. J. Farr (Eds.), Aptitude, learning, and instruction, Vol. 3, conative and affective process analysis (pp. 223-53). Hillsdale, NJ: Lawrence Erlbaum.

Metzger, E. C., Lubin, L., Patten, R. T., \& Whyte, J. (2016). Applied gamification: Creating reward systems for organizational professional development. In D. Ifenthaler, N. Belin-Mularski, \& D. Mah (Eds.) Foundation of digital badges and micro-credentials (pp. 457-66). NYC, NY: Springer International Publishing. doi: 10.1007/978-3-319-15425-1.

Moss, P. A. (2003). Reconceptualizing validity for classroom assessment. Educational Measurement: Issues and Practice, 22(4), 13-25. doi: 10.1111/j.1745-3992 .2003.tb00140.x

National Research Council. (2001). Knowing what students know: The science and design of educational assessment. Washington, DC: National Academies Press.

Nicholson, S. (2012). A user-centered theoretical framework for meaningful gamification. Games, Learning \& Society, 8(1), 223-30.

Nolen, S. B., Horn, I. S., \& Ward, C. J. (2015). Situating motivation. Educational Psychologist, 50(3), 234 47. doi: 10.1080/00461520.2015.1075399.

Olneck, M. (2015). Whom will digital badges empower? Sociological perspectives on digital badges. In D. T. Hickey, J. Jovanovic, S. Lonn, \& J.E. Willis, III (Eds.), Proceedings of the Second International Open Badges in Education Workshop (pp. 5-11), Workshop, Poughkeepsie, NY. Retrieved from http://ceur-ws.org/ Vol-1358/paper1.pdf

Oyserman, D. (2015). Pathways to success through identity-based motivation. Oxford, UK: Oxford University Press.

Pink, D. H. (2011). Drive: The surprising truth about what motivates us. New York, NY: Penguin.

Ravet, S. (2014). \#Openbadges for key competencies. Learning futures: Reflections on learning, technologies, identities, and trust [blog post]. Retrieved from http:// www.learningfutures.eu/2014/12/openbadges-for-key-competencies/ 
Ravet, S. (2015). \#OpenBadges: Beyond "Spray and pray"! Learning futures [blog post]. Retrieved from www.learningfutures.eu/2015/02/openbadges-beyond-sprayand-pray.

Resnick, M. (2012). Still a badge skeptic [blog post]. Retrieved from http://hastac.org/ blogs/mres/2012/02/27/still-badge-skeptic.

Rieber, L. P. (1996). Seriously considering play: Designing interactive learning environments based on the blending of microworlds, simulations, and games. Educational Technology Research and Development, 44(2), 43-58. doi: 10.1007/BF02300540.

Shavelson, R. J., Baxter, G. P., \& Pine, J. (1992). Research news and comment: Performance assessments: Political rhetoric and measurement reality. Educational Researcher, 21(4), 22-7. doi: 10.3102/0013189X021004022.

Shepard, L. A. (2000). The role of assessment in a learning culture. Educational Researcher, 29(7), 4-14.

Silva, E., White, T., \& Toch, T. (2015). The Carnegie Unit: A century-old standard in a changing educational landscape. New York: Carnegie Foundation for the Advancement of Teaching. Retrieved from www.carnegiefoundation.org/ resources/publications/carnegie-unit.

Skinner, B. F. (1953). Science and human behavior. Santa Monica, CA: Simon and Schuster.

Steele, J. L., Lewis, M., Santibanez, L., Faxon-Mills, S., Rudnick, B., Stecher, B., \& Hamilton, L. (2014). Competency-based education in three pilot programs: Examining implementation and outcomes. Santa Monica, CA: RAND Corporation. Retrieved from www.rand.org/pubs/research_reports/RR732 .html.

Thigpen, K. (2014). Digital badge systems: The promise and potential. Washington, DC: The Alliance for Excellent Education. Retrieved from http://all4ed.org/ wp-content/uploads/2014/11/DigitalBadgeSystems.pdf.

Todorov, J. C. (2013). Conservation and transformation of cultural practices through contingencies and metacontingencies. Behavior and Social Issues, 22, 64-73. doi: 10.521/bsi.v.22i0.4612.

Torrance, H. (2012). Formative assessment at the crossroads: Conformative, deformative and transformative assessment. Oxford Review of Education, 38(3), 32342. doi: 10.1080/03054985.2012.689693.

Tran, C., Schenke, K., \& Hickey, D. T. (2014). Design principles for motivating learning with digital badges: Consideration of contextual factors of recognition and assessment. In J. L. Polman, E. A. Kyza, D. K. O’Neill, I. Tabak, W. R. Penuel, A. S. Jurow, ... L. D'Amico (Eds.), Learning and becoming in practice: The International Conference of the Learning Sciences (ICLS) 2014, Volume 1 (pp. 1027-1032). Boulder, CO: The International Society of the Learning Sciences.

Xenos, M. \& Foot, K. (2008). Not your father's Internet: The generation gap in online politics. In W. L. Bennett (Ed.), Civic life online: Learning how digital media can engage youth, (pp. 51-70). Cambridge, MA: The MIT Press.

Young, J. R. (2012). "Badges" earned online pose challenge to traditional college diplomas. The Education Digest, 78(2), 48-52.

Yowell, C. M. (2014). Presentation at the Open Badges Summit to Reconnect Learning. Retrieved from http://vimeo.com/87127953.

Yowell, C. M. \& Smylie, M. A. (1999). Self-regulation in democratic communities. The Elementary School Journal, 99(5), 469-90. doi: 10.1086/461936. 